\title{
A avaliação da educação superior em escala global: da acreditação aos rankings e os resultados de aprendizagem ${ }^{1}$
}

\author{
Gladys Beatriz Barreyro
}

Resumo: Desde as décadas finais do século XX, a globalização tem impactado as políticas educacionais, criando uma agenda globalmente estruturada para a educação (DALE, 2010). Nos sistemas educativos nacionais surgiu preocupação pela avaliação e, no caso da educação superior, políticas relativas à aferição da sua qualidade começaram em torno dos anos de 1980, sendo essa a primeira fase do Estado Avaliador (AFONSO, 2013; NEAVE, 2012). Nesse marco, o texto analisa as tendências atuais de avaliação da educação superior em nível global desde fins do século XX até o presente, através de três políticas: a acreditação/avaliação da educação superior; os rankings internacionais de universidades e a avaliação de resultados de aprendizagem. Pretende-se analisar essas três políticas e verificar se elas estão conduzindo a educação superior à fase pós-Estado Avaliador (AFONSO, 2013), em que cada vez os Estados Nacionais terão menos autonomia perante outras instituições que compõem a governança global da educação superior (DALE, 2010).

Palavras-chave: Qualidade da educação superior. Rankings. AHELO.

\section{Global higher education evaluation: on accreditation, rankings and learning outcomes}

Abstract: Since the last decades of the twentieth century, globalization has impacted the educational policies, creating a globally structured agenda for education (DALE, 2010). Around the 1980's, the concern about evaluation appeared in national education systems. At the same time, in the case of higher education, policies of quality assurance started to be created. Those policies are considered as the first phase of the Evaluative State (AFONSO, 2013; NEAVE, 2012). In this framework, the paper analyses the current trends in evaluation of higher education on a global level, since the late twentieth century to the present, by means of three policies: the accreditation/evaluation of higher education; the international rankings of universities, and the assessment of student learning outcomes. I intend to verify whether those three policies are leading higher education to the post Evaluative State-phase (AFONSO, 2013), in which nation-states would have less autonomy than other institutions that make up the global governance of higher education (DALE, 2010).

Key words: Quality in Higher education. Accreditation. Rankings.

Este é um artigo publicado em acesso aberto sob uma licença Creative Commons https://creativecommons.org/licenses/by-nc/4.0/

${ }^{1} \mathrm{O}$ texto é uma versão corrigida e ampliada do trabalho intitulado Educação superior, internacionalização e qualidade: AHELO, ENADE global ou PISA da educação superior?, apresentado no GT 11 Políticas de Educação Superior, na $37^{\text {a }}$ Reunião Anual da Anped, ocorrida de 4 a 8 de outubro de 2015, em Florianópolis. Foi elaborado durante estágio senior apoiado pela Capes, no Center for International Higher Education do Boston College, EUA, em 2014/5. 


\section{Introdução}

A crise do Estado de bem-estar social no mundo ocidental gerou a diminuição dos gastos na área social e, portanto, na educação. O controle desse gasto, agora menor, trouxe políticas de accountability, como as avaliações nos sistemas educativos nacionais (Estado Avaliador), surgidas nas décadas de 1980 e 1990, na América Latina, decorrentes de reformas de Estado neoliberais.

Roger Dale introduz o conceito de agenda globalmente estruturada da educação para fazer referencia ao tipo de governança supranacional que mudou o papel dos estados nacionais no governo da educação, pois outras instituições intervêm elaborando, propondo e/ou financiando políticas educativas e fornecendo ênfases e modelos de educação. Elas, tais como a Organização Mundial de Comércio (OMC), a Organização para a Cooperação e Desenvolvimento Econômico (OECD), o Banco Mundial (BM), a UNESCO, ONG's e Fundações têm atuação global e geram uma governança sem governo (ROBERTSON; DALE, 2013). Os Estados Nacionais e governos interpretam e traduzem as propostas das organizações internacionais de acordo com as prioridades nacionais (DALE, 2010).

Contudo, não se trata de uma convergência, pois não há relação hierárquica entre os modelos regionais, nacionais e globais. Dale assinala também a necessidade de examinar as relações mutuas e evitar concepções simplórias de difusão, uma vez que "é possível a existência de discursos distintos ou paralelos, ou até mesmo híbridos” (DALE, 2009, p. 411).

Especificamente quanto à educação superior, na globalização, os processos de acumulação flexível e a emergência da sociedade do conhecimento geraram o desenvolvimento de uma economia do conhecimento, com a consequente necessidade de profissionais do conhecimento, o que colocou a educação superior no centro das atenções. Se a educação superior tinha a finalidade de reprodução de valores e formação de recursos humanos, como foi até a década de 1980, no final do século XX passou a ser essencial na criação de conhecimentos requeridos pelo mercado (RAMA, 2006).

A educação superior, além de ser prioritária na sociedade de conhecimento, tornou-se uma mercadoria, para o que contribuiu o GATS (General Agreement on Trade in Services ou Acordo Geral sobre Comércio em Serviços). As negociações realizadas no marco da $\mathrm{OMC}^{2}$

\footnotetext{
${ }^{2}$ A OMC criada em 1995, deriva do Acordo Geral sobre Tarifas e Comércio (General Agreement on Tariffs and Trade, GATT), estabelecido em 1947 com o objetivo de favorecer a liberalização comercial. Funcionou organizado em Rodadas. A Rodada Uruguai foi encerrada quando foi criada a Organização Mundial do
} 
incluíram a educação no âmbito da liberação de comercio e serviços (DIAS, 2003), em que, com tal propósito, deu-se prioridade à educação superior (BATISTA, 2012) ${ }^{3}$. Portanto, a educação superior antes considerada um bem público, passou a ser considerada como um bem privado, uma mercadoria “sujeita as regras do comercio" (GINKEN; DIAS, 2006, p. 37).

A circulação de profissionais na economia global é outro fato decorrente da globalização, centrada não na fuga de cérebros (brain drain), mas na competição pelos cérebros $(\text { brain race })^{4}$, pois

\&\#091;...\&\#093; as economias do conhecimento dos países membros da OECD requerem pessoas altamente qualificadas e, devido ao envelhecimento da sua população e à diminuição do interesse da sua juventude pelas ciências duras, não há suficientes; razão pela qual se tornaram necessários imigrantes altamente qualificados ${ }^{5}$ (CHOUDANA; WIT, 2014, p. 23).

Vários países têm restringido a imigração não qualificada e gerado procedimentos para facilitar a qualificada, como a criação de novos tipos de vistos, bolsas e outras ajudas que facilitam a permanência de estudantes internacionais. Os países da OECD registram a permanência de $25 \%$ dos estudantes internacionais no país a que se dirigiram para estudar (CHOUDANA; WIT, 2014).

Fraudes nas titulações, verificadas desde a primeira década do século, têm gerado preocupação com as "fábricas de diplomas" e levado à descoberta da existência de falsas agencias de acreditação que garantem (falsamente) a qualidade do diploma, contribuindo a revitalizar a preocupação pela garantia da qualidade num mundo global.

$\mathrm{Na}$ agenda global da educação a avaliação é uma das prioridades de política. Na educação superior começou a ser desenvolvida nas décadas de 1980 e 1990 em países europeus e latino-americanos, com a criação de sistemas e agências de acreditação, o que foi denominado por Neave (2012) como Estado Avaliador. Para Afonso (2013), essa constituiu a primeira etapa do Estado Avaliador na qual os estados nacionais tinham mais autonomia.

Comércio que continua tentando liberar mais serviços ao comércio internacional. No âmbito da OMC foi estabelecido o GATS.

${ }^{3}$ As negociações continuam e os países individualmente podem escolher alguns serviços (ou aspectos deles) para serem liberados. Existem atualmente países que tem liberado mais do que os outros, mas na prática, a mercantilização da educação superior é fato, tendo prescindido da aceitação formal do GATS, como pode ser visto no Brasil, no caso das oligopólicas Anghanghera, Kroton e outras.

${ }^{4}$ Em bibliografias da área de gestão, é traduzida como competição pelos talentos.

${ }^{5}$ As versões para o português dos textos em inglês são minhas. 
Mas, os efeitos da globalização na educação superior levaram as políticas de avaliação de serem políticas induzidas nos Estados nacionais (na primeira etapa do Estado Avaliador) a uma preocupação em nível global que estabelece relações de escala com os níveis nacional e regional (ROBERTSON; DALE, 2013), na segunda etapa do Estado Avaliador.

Nas palavras de Afonso (2013, p. 174):

$\& \# 091 ; . . \& \# 093$; nessa segunda fase, o Estado-avaliador passa a ser confrontado de forma mais clara com os efeitos externos sobre as políticas educativas \&\#091;..\&\#093; os quais emergem em contexto de globalização vinculados muito fortemente às transformações socioeconômicas, tecendo e intensificando novas relações entre o nacional e o global.

$\mathrm{O}$ autor considera que as políticas de avaliação estão ampliando e aprofundando o Estado Avaliador e vislumbra uma etapa posterior (pós-Estado Avaliador) em que a avaliação fugirá cada vez mais da decisão dos Estados Nacionais, especialmente nos países periféricos. (AFONSO, 2013)

Com este texto apresentam-se alguns resultados parciais de uma pesquisa em andamento $^{6}$ com o intuito de mostrar as tendências observadas nas últimas duas décadas em relação com a agenda global para a educação superior, no que diz respeito à avaliação. Assim, são recuperadas e analisadas algumas propostas, discussões e ações de avaliação e garantia de qualidade que mostram tendências em escala global, tais como: 1) a acreditação/avaliação, 2) os rankings internacionais de universidades e 3) a possível (futura) prova para os estudantes da educação superior em nível global: o Assesstment of Higher Education Learning Autcomes (AHELO), que está sendo delineado pela OECD.

\section{Acreditação/Avaliação ${ }^{7}$}

Os processos de acreditação/avaliação para garantia de qualidade na educação superior começaram a se desenvolver nos anos de 1980, na Europa, com a criação de sistemas nacionais de avaliações externas e agências em diversos países europeus (França, Holanda, Dinamarca), inspirados nos modelos de acreditação que haviam sido desenvolvidos pelas instituições de educaçao superior nos Estados Unidos como uma forma de auto-regulação,

\footnotetext{
${ }^{6}$ A pesquisa utiliza fontes bibliográficas, documentais e entrevistas.

7 Embora existam diferenças nos processos de acreditação e de avaliação, aqui elas compõem uma única categoria porque se utilizam dos mesmos procedimentos: avaliação institucional ou de cursos, com autoavaliação e avaliação externa (visitas de pares). A função da acreditação é constatar e verificar se a instituição ou curso cumpre ou não com os parâmetros de qualidade previamente definidos.
} 
desde finais do século XIX. Na América Latina, foi nos anos de 1990 que foram criadas as primeiras políticas de avaliação, por exemplo, em Argentina, Chile, Brasil, no contexto de reformas do Estado inspiradas pelas políticas neoliberais de ajuste estrutural latinoamericanas.

No Brasil, começaram nos anos de 1990 com a criação do Programa de Avaliação Institucional das Universidades Brasileiras (PAIUB) que promeveu processos de avaliação institucional em Universidades e seguiu com o Exame Nacional de Cursos (Provão) - que visava controlar a qualidade da expansão do setor privado, e a massificação, próprias do que Rama (2006) chama de segunda reforma da educação superior latino-americana - e que derivou no atual Sistema Nacional de Avaliação da Educação Superior (SINAES).

Para Afonso (2013, p. 271-2):

\begin{abstract}
Nos países que iniciaram, há mais de duas décadas atrás, a vaga de reformas neoliberais e neoconservadoras, a avaliação constitui-se ela própria como uma política estatal, enquanto instrumento da ação dos Estados e governos, tendo muito a ver com leituras internas das especificidades nacionais, ainda que filtradas e interpretadas por novas orientações ideológicas então emergentes - nas quais, em certos casos, os aspectos simbólicos foram ampliados (e dramatizados) por oposição a outras realidades nacionais.
\end{abstract}

Após o GATS e as negociações para a liberação da educação como serviço comercial, em 1995, a questão mudou, pois já não era suficiente a acreditação/avaliação em nível nacional.

Então, houve encontros e iniciativas, idéias e tentativas de encaminhar a questão, que podem ser (muito) resumidas nas propostas de criação de: a) um acreditador global; b) acreditações regionais; c) meta-acreditação de agencias; d) redes de agências de acreditação; e) diretrizes ou guias de "boas práticas" de acreditação (internacionais, regionais ou nacionais).

A proposta de um acreditador global existiu, teve problemas de legitimidade e não obteve consenso (GINKEN; DIAS, 2006).

Acreditações regionais foram implementadas, como é o caso do Mercosul que criou o Mecanismo Experimental de Acreditação de Cursos Universitários (MEXA) e o Sistema de Acreditação Regional de Cursos Universitários do Mercosul (ARCU-SUL), do qual o Brasil participa. Cursos universitários de Agronomia, Veterinária, Enfermagem, Medicina, Engenharia e Arquitetura têm conseguido a acreditação Mercosul (PORTAL MEC, 2015). Para Hermo (2011), o MERCOSUL Educacional é uma das primeiras iniciativas de convergência em nível regional e, inclusive, sendo seus processos um antecedente levado em consideração para o processo de integração da educação superior europeia. Contudo, o Brasil 
continua com sua política (SINAES) em escala nacional e com poucos efeitos do regional ARCU-SUL.

Na Europa, existem processos de meta-acreditação de agências, ou seja, processos de avaliação que uma agência faz de outras como no caso da Associação Europeia para a Garantia da Qualidade na Educação Superior (ENQA) Essa agencia européia foi criada em 2000 por sugestão do Conselho Europeu e, posteriormente, a pedido dos ministros de educação, elaborou diretrizes de boas práticas para as agencias de acreditação européias, nacionais ou sub-regionais. Para fazer parte do Registro Europeu de Agências de Garantia de Qualidade (EQAR), as agências têm que passar pelo processo de meta-acreditação que faz a ENQA e que tem prazo limitado de validade (EQAR, 2015). Isto é importante, pois são as agências acreditadas que garantem a acreditação de cursos e instituições no Espaço Europeu.

É interessante analisar a micropolítica do poder nesse processo regional. Num primeiro momento, os ministros fazem o pedido para a agencia elaborar as Diretrizes, depois eles as adotam e aprovam. Depois entra o Registro e, para fazer parte dele, as agencias devem ter feito meta-avaliação. Ou seja, não há imposição, há adoção pelos ministros europeus, de diretrizes feitas por um órgão supostamente técnico e neutro. E para terem mais legitimidade e evitar suspeitas de serem agencias falsas, elas precisam entrar no Registro. Ainda, como a existência de uma agencia nacional de acreditação é uma das Diretrizes da ENQA, criaram-se ou reformularam-se as agências nacionais seguindo essas Diretrizes, como no caso de Portugal. A proposta brasileira de criação do Instituto Nacional de Supervisão e Avaliação da Educação Superior - INSAES (BRASIL, 2012), pode ser entendida nesta perspectiva de agenda global. Tanto as práticas da União Europeia propagadas pela ENQA, quanto as do ARCU-SUR, requerem uma agencia de acreditação. O Brasil não tem e realiza essas funções por meio de diversos órgãos da estrutura do Ministério da Educação (BARREYRO et al., 2015). O INSAES está atravessado por essa conjuntura, mas o projeto de criação apresenta os traços da política de educação superior do País, mais regulatória do que avaliativa (SGUISSARDI, 2013), diferentemente das agências de avaliação em versões européias e latino-americanas. Resta saber se esse Instituto, caso venha a ser aprovado e implementado, terá características da política do País, em que agencias, supostamente técnicas, nem sempre são dirigidas por pessoas com perfil técnico.

Ainda, em nível global existem Redes de Agencias, que são associações de instituições e são também um modo sutil de divulgar e induzir procedimentos de avaliação, como a Rede 
Internacional de Agencias de Garantia de Qualidade da Educação Superior - INQAAHE ${ }^{8}$ e a Rede Ibero-americana de Garantia da Qualidade da Educação Superior - RIACES ${ }^{9}$, dentre outras, pois existem em todas as regiões e sub-regiões do planeta.

O Guia para a Qualidade na Provisão de Educação Superior Transfronteiriça ${ }^{10}$ é outro exemplo de diretrizes indutoras. No caso, ela foi elaborada pela OECD e divulgada pela UNESCO.

Percebe-se, então, no caso da acreditação de instituições e cursos a existência de políticas em escalas regionais e nacionais e de redes internacionais de indução (soft power) e divulgação de práticas de acreditação

\section{Rankings globais}

Os rankings globais de universidades são uma tentativa de avaliação de qualidade em nível global. Surgiram na primeira década do século XXI, gerando ampla difusão e rápida aceitação, embora rankings existam desde o século XIX, nos EUA, e os rankings nacionais ganharam importância desde a década de 1990, em diversos países. Há pelo menos dez rankings internacionais e mais de 50 nacionais. Os rankings são tabelas de classificação de instituições, organizados por nota obtida mediante variáveis selecionadas; são criados por governos, universidades, órgãos de financiamento e imprensa (U.S. News and World Report, desde 1981; Folha de S. Paulo, desde 2012).

O movimento dos rankings globais começou com o interesse do governo chinês em enviar estudantes a instituições estrangeiras, o que deu origem ao Academic Ranking of World Universities (ARWU), da Shangai Jiao Tong University que, desde 2003, avalia a pesquisa em universidades. Ele foi idealizado por dois professores e um técnico, com dados públicos e gratuitos: por isso privilegia a pesquisa, as publicações em inglês (especialmente nas revistas Nature e Science) e a quantidade de prêmios Nobel que trabalham ou estudam na instituição. É considerado constante, consistente e transparente pela sua forma de coleta de dados. Ele ignorava as ciências sociais e as humanidades, mas passou a considerá-las desde 2011 na forma de citações (ALTBACH, 2012).

\footnotetext{
${ }^{8}$ International Network for Quality Assurance Agencies in Higher Education, criada em 1991, em Hong Kong, foi transferida para a Irlanda, em 2003. Atualmente, está sediada em Barcelona, Espanha.

${ }^{9}$ Red Iberoamericana de Aseguramiento de la Calidad de la Educación Superior.

${ }^{10}$ Guidelines for quality provision in cross border higher education.
} 
Outros, destacados em nível internacional, são o The Times Higher Education World University Ranking, desenvolvido pelo jornal inglês The Times e o QS World's University Ranking. Segundo Altbach (2012), o primeiro considera o impacto das citações de artigos e os fundos destinados à pesquisa, além de perguntas a acadêmicos de diversos países acerca das instituições. Recentemente, incluiu a relação do número de discentes por docente e o número de docentes estrangeiros. Mas seus resultados têm sido bastante questionados pelas informações que coleta. $\mathrm{O}$ segundo está baseado principalmente na opinião de acadêmicos do mundo inteiro sobre a reputação das instituições. Ele é realizado por uma agência com fins lucrativos que recruta estudantes internacionais e possuiu um programa de melhoria de instituições de educação superior (ALTBACH, 2012), o que mostra certo conflito de interesses.

Os rankings valorizam aspectos como a reputação e o status das instituições; são simples e claros:

As classificações são muito sedutoras talvez por sua facilidade de utilização. Não é realista esperar que 'os consumidores' do ensino superior examinarão relatórios de auto-avaliação ou os relatórios preenchidos por avaliadores externos comparando instituições. As classificações fornecem respostas fáceis. Elas mostram aos estudantes em potencial que uma universidade classificada na quinta posição é melhor do que uma na vigésima primeira (REISBERG, 2011, p. 17, grifo da autora).

Mas eles são alvos de muitas críticas. Dentre as técnicas, Harvey (2008) assinala: a) a seleção de indicadores, que é feita a partir dos disponíveis, mas não dos necessários; b) o fato de usar índice de citações em língua inglesa, o que prejudica instituições de diversos países e favorece os países anglófonos; e c) o número de prêmios Nobel da instituição, o que beneficia as instituições estadunidenses e inglesas. Os rankings também dão pesos arbitrários a cada indicador e eles variam muito de um ranking para outro: um dá $16 \%$ de peso à graduação, outro $2 \%$. Alguns mudam os indicadores de um ano para outro, o que tira a possibilidade de fazer comparações históricas, questão que - em geral - não é levada em conta por quem lê ou divulga os resultados.

Contudo, os rankings avaliam pesquisa e estão contribuindo para o fortalecimento de um modelo emergente de educação superior: as universidades de pesquisa, também chamadas de universidades de classe mundial. Elas são consideradas por alguns como a instituição central na economia do conhecimento por questões tais como a geração de patentes: em setores como a biotecnologia, elas superam as empresas (ALTBACH; SALMI, 2011). As universidades de pesquisa possuem:

\&\#091;...\&\#093; professores altamente qualificados, resultados de excelência em pesquisa, qualidade no ensino e na aprendizagem, altos níveis de financiamento governamental e não governamental, estudantes internacionais e talentosos, liberdade acadêmica, estrutura de 
governança autônoma e instalações bem equipadas para ensino, pesquisa, administração e muitas vezes - para alojamento estudantil (ALTBACH; SALMI, 2011, p. 3).

Segundo Altbach (2011), são instituições em que a pesquisa é central. Produzem pesquisa original em ciência básica e aplicada e recebem volumosos fundos para pesquisa, liderando os avanços tecnológicos. São o nexo entre a ciência global e os sistemas nacionais de ciência. São instituições de elite e meritocráticas que se dedicam ao ensino de pósgraduação e atendem a poucos, mas os melhores, estudantes de graduação. Possuem os acadêmicos mais qualificados, que ministram no máximo duas disciplinas por ano, destinando seu tempo à pesquisa e à publicação de resultados. Nessas instituições, o inglês é a lingua franca, à maneira do latim nas instituições medievais.

Os rankings têm introduzido a lógica da competição entre instituições numa perspectiva global e gerado impactos nas políticas nacionais e institucionais, apesar de suas limitações metodológicas:

\begin{abstract}
$\& \# 091 ; . . \& \# 093$; as tecnologias dos rankings de universidades podem ser vistas como projetos sociais e políticos começando em uma localização espacial específica, se desenvolvendo rapidamente através de processos endógenos \&\#091;...\&\#093; e transformando ambos os contextos: aquele em que começa e os ambientes em que penetram (ROBERTSON; OLDS, 2012, p. 5).
\end{abstract}

No Brasil, os rankings têm tido grande apelo, desde o ranking da revista Playboy, passando pelos rankings feitos e divulgados pela imprensa com os resultados do Provão, o ranking que o MEC divulgou com resultados do Índice Geral de Cursos da Instituição (IGC) do SINAES, em 2008, e o atual ranking da Folha de S. Paulo.

Ainda, o resultado em rankings internacionais influencia políticas nacionais como o acordo da Capes e a Usp para vinda de professores estrangeiros (CAPES, 2015). Há impactos nas instituições, especialmente naquelas que privilegiam a pesquisa e estão entre as que aspiram subir nos rankings. Curiosa é sua influência em premiações e remunerações. Por exemplo, em 2008, a Universidade de São Paulo instituiu o Prêmio de Excelência Institucional na forma de bônus pago a professores e funcionários baseado em indicadores de desempenho da Universidade, dentre os quais:

\&\#091;...\&\#093; a posição ocupada pela USP nos quatro rankings internacionais selecionados, que avaliam ensino e pesquisa, entre outros indicadores, a saber: Webometrics Ranking of World, Institute of Higher Education da Shanghai Jiao Tong University, Higher Education Evaluation \& Accreditation Council of Taiwan, e The Times Higher Education (USP, 2008).

Os rankings também justificaram o não pagamento do mesmo prêmio no ano de 2010, porque a Comissão gestora considerou que não havia havido evolução positiva na posição da 
instituição nos rankings (CRUZ, 2010). Já em 2014 ele não foi pago devido à crise financeira da universidade, enquanto, simultaneamente, a instituição divulgava quantos lugares ela havia avançado em vários dos rankings! (USP, 2014).

Assim, os rankings funcionam em escala global, mas geram consequências e políticas em outras escalas como as institucionais em que, claramente, se percebe a influência dos atores locais na ressignificação deles, como no caso da USP.

\section{Rumo ao $P I S A^{11}$ da Educação superior (com lembranças do ENADE ${ }^{12}$ )}

Tanto a acreditação quanto os rankings teriam limites no que diz respeito à qualidade em nível global. A acreditação de instituições e cursos limitaria sua atuação para determinar a aptidão ou não para funcionamento, com poucas consequências para a melhoria da qualidade: apenas serviria para certificar que um curso ou instituição tem as condições mínimas para funcionar. Já rankings internacionais pretendem avaliar a excelência, ou seja: as instituições de pesquisa ao redor do mundo, mas não todas as instituições de educação superior. Haveria um déficit de informações sobre o ensino e a aprendizagem em âmbito global, num momento de massificação da educação superior, segundo a OECD (2013). Diante da

$\& \# 091 ; \ldots \& \# 093$; necessidade de contar com uma força de trabalho futura que sustente o desenvolvimento, o crescimento e a prosperidade na economia global e a coesão social, pois os estudantes devem adquirir as habilidades necessárias com a finalidade de contribuir para o progresso econômico, científico e social, dado o grande investimento de governos e indivíduos na educação superior (OECD, 2012, p. 2).

Os Ministros da Educação dos países da $\mathrm{OECD}^{13}$ iniciaram a discussão sobre a avaliação dos resultados de aprendizagem, o que levou à proposta de criação de uma prova: o AHELO (Assessment of Higher Education Learning Outcomes)

${ }^{11}$ O Programa de Avaliação Internacional de Estudantes (Program for International Student Assesstment) é uma avaliação aplicada a cada três anos a estudantes de 15 anos de idade, selecionados aleatoriamente, em 70 países (ou região/cidade de alguns países,) com o objetivo de "avaliar os sistemas educacionais ao redor do mundo, testando as habilidades e conhecimentos dos estudantes” (OECD, 2015). Cada aplicação é feita numa disciplina diferente: leitura, matemática e ciência. Foi criada e é aplicada pela OECD,

${ }^{12}$ Exame Nacional de Desempenho dos Estudantes é um dos componentes do Sistema de Avaliação da Educação Superior brasileiro (SINAES) e consta de uma prova aplicada aos alunos concluintes de cursos de graduação selecionados a cada ano.

${ }^{13}$ A OECD - Organisation for Economic Co-operation and Development foi criada em 1961, quando os Estados Unidos e Canadá incorporaram-se a uma organização prévia, que havia sido criada em 1948 para implementar o Plano Marshall na Europa. Seu objetivo "é promover políticas para a melhora do bem-estar econômico e social das populações do mundo" Atualmente são 34 países que compõem a OECD, mas há outros países vinculados como parceiros preferenciais, dentre os quais o Brasil. Desenvolve projetos em diversas áreas, dentre as quais a Educação. 
A Avaliação de Resultados de Aprendizagem da Educação Superior - AHELO seria "uma avaliação direta do desempenho dos alunos em nível global e válida em diversas culturas, línguas e diferentes tipos de instituições" para que eles saibam "o que sabem e o que podem fazer após a graduação" (OECD, 2013, p. 3).

A proposta foi desenvolvida por especialistas internacionais em avaliação em larga escala transnacional e foram realizados, entre 2010 e 2012, estudos de viabilidade pelo Consórcio AHELO da OECD, financiado por diversas entidades. ${ }^{14}$

A prova foi aplicada como pré-teste, em diferentes línguas, a estudantes do último ano de cursos de engenharia e economia, de 17 países. Os testes constam de uma parte que avalia habilidades gerais e, outra parte, habilidades específicas.

Segundo a OECD, as habilidades gerais consideram as competências necessárias para o mundo de trabalho: raciocínio analítico, solução de problemas, pensamento crítico. Isso permitiria incluir todo o universo de estudantes de cursos de três ou quatro anos, apesar das diferenças nacionais, pois alguns países iniciam a formação profissional após esse período.

Quanto à avaliação dos conhecimentos disciplinares, a OECD reconhece a diversidade de currículos, cursos e instituições no mundo acerca dos conhecimentos específicos e argumenta que a organização curricular em competências permitiria fazer avaliações internacionais "tem se feito progresso nesse assunto, usando o projeto Tuning, ${ }^{15}$ que foi aplicado com sucesso na Europa em diversas áreas e agora é desenvolvido em outras partes do mundo" (LALANCETTE, 2010, p. 43). Com efeito, foi proposta a realização de um projeto AHELO Tuning para tal fim $^{16}$, contudo embora exista o projeto Tuning, não pode se considerar que ele seja mundialmente aplicado.

O AHELO também coletaria informações contextuais mediante aplicação de questionário a alunos. Também pretende fazer pesquisas sobre valor agregado, entendido

\footnotetext{
${ }^{14}$ Fundação Lumina para a Educação (EUA), Compagnia di San Paolo (Italia), Fundação Calouste Gulbenkian (Portugal), Riksbankens Jubileumsfund (Suécia), Fundação Spencer e Teagle (EAA), Higher Education Founding Council for England - HEFCE (Inglaterra), Higher Education Authority - HEA (Irlanda) e Fundação William e Flora Hewlett (EUA).

${ }^{15} \mathrm{O}$ projeto Tuning surgiu na Universidade de Deusto, na Espanha. Propõe criar perfis profissionais articulados por meio de competências genéricas e específicas nos cursos superiores, que permitam a comparabilidade entre eles. Propõe a convergência da educação superior, a integração e a criação de currículos em áreas e cursos selecionados. Tem atuado na Europa, na América Latina (com o projeto Tuning América Latina) e em outras regiões e/ou países.
}

${ }^{16}$ A Fundação Lumina que financiou o Estudo do AHELO também apóia o projeto Tuning. 
como "a contribuição que a instituição faz nos resultados obtidos pelos alunos, controlando suas habilidades prévias" (OECD, 2013, p. 7).

A unidade de análise seria a instituição e não os estudantes. Não haveria possibilidade de fazer comparações entre países. A participação de países e institutições seria voluntária.

As semelhanças com ENADE brasileiro são evidentes: documentos da OECD mencionam o Provão e o ENADE, como mostra Nusche (2008) em estudo realizado para a Organização, acerca de provas aplicadas na Austrália, Canadá, México, Estados Unidos, Inglaterra e Brasil. Contudo, é bom ressaltar que: 1) o uso de provas em larga escala na avaliação da educação superior não é uma prática generalizada como é no caso da educação básica em âmbitos nacionais; e 2) o uso de resultado de provas para a regulação da educação superior parece ser uma criação brasileira.

Com efeito, os quatro componentes da proposta $A H E L O$ são similares aos do ENADE que aplica prova de habilidades gerais, prova de habilidades específicas, questionário aos estudantes e estudos de valor agregado como o Índice de Diferença de Desempenho (IDD). A proposta AHELO seria aplicada aos estudantes do último ano do curso, como foi o caso do Provão e é o caso do Enade ${ }^{17}$.

Mas, é importante ressaltar que a prova de habilidades gerais, utilizada no pré-teste não foi criada especialmente para o AHELO, pois foi aproveitada uma do Collegiate Learning Assessment (CLA), prova aplicada nos Estados Unidos, voluntariamente, em instituições e cursos e que permite comparações.

Contudo, o AHELO parece um ENADE global ou um PISA da educação superior.

As críticas às avaliações em larga escala já são conhecidas por nós desde a época do Provão, e elas seriam extensivas ao AHELO. O próprio projeto assinala algumas, tais como: a) risco de os resultados serem usados como um ranking, apesar de não serem desenhados para isso; b) risco de que seja privilegiado o ensino em detrimento de outras funções das instituições; c) realização de comparações entre instituições muito diferentes; d) informações limitadas ou simplificação das conclusões; e) impacto na autonomia institucional e a liberdade acadêmica; f) padronização de cursos em nível global colocando em perigo a criatividade e a inovação. Ainda a Organização assinala que diferentes tradições nacionais de educação

\footnotetext{
${ }^{17}$ Entre 2004 e 2010, o ENADE foi aplicado aos alunos do primeiro e do último ano do curso. A Portaria MEC n. 40/07, republicada em 2010, determinou que passasse a ser aplicado apenas para os estudantes do último ano.
} 
superior poderiam questionar a avaliação de habilidades gerais, independentemente das disciplinas específicas dos cursos (OECD, 2013).

Os problemas técnicos e de financiamento, em meio à crise econômica no mundo desenvolvido, pareciam ter esfriado o andamento da proposta, mas novas reuniões de discussão ocorreram em 2014 e 2015. Em setembro de 2015, ele foi adiado por falta de participantes (MORGAN, 2015).

Propositalmente, foram descritos nesta seção os procedimentos relatados pela OECD para criação do AHELO e que destacam: a) a expertise dos que elaboraram a prova, pertencentes à elite das universidades de pesquisa; b) a busca de consensos; c) os estudos e pré-testes; e d) o reconhecimento dos problemas de uma avaliação desse tipo. Tais estratégias tendem a mostrar tecnicismo e objetividade, busca de consensos, participação voluntária. Em suma: indução.

A perspectiva de uma prova global aplicada a cursos tradicionais e profissionais não parece tão improvável, após se terem elaborado propostas e realizado pré-testes. Também foram cursos profissionais os participantes do MEXA e do ARCU-SUL e não é muito difícil imaginar o interesse da OECD e outras organizações em poder avaliar a formação nessas áreas, haja vista o desenvolvimento da economia do conhecimento. Alguns, inclusive, consideram apropriado ter um parâmetro internacional na formação profissional de profissões de risco para a sociedade, como médicos e engenheiros ${ }^{18}$.

É de supor que os políticos nacionais dificilmente dispensem os produtos de agências, que são percebidas como estruturas independentes e de expertise. Agências estas que lhes fornecem recursos para pensarem a realidade educacional e para expressarem as suas orientações, mas que o fazem, porém, em nome da "independência" e do "cosmopolitismo" do saber dos peritos (CARVALHO, 2009, p. 1030, grifos do autor).

\section{Considerações finais}

A avaliação da educação superior integra a agenda global da educação no século XXI, apresentando diversas tendências que se verificam em escala global, regional, nacional e institucional. Assim, a acreditação apresenta-se em escala regional e nacional, destinada à avaliação de instituições e cursos, os rankings internacionais existem em escala global e têm consequências em outras escalas, como a institucional. A brecha entre pesquisa e ensino tem

\footnotetext{
${ }^{18}$ Embora, consideremos que todas as profissões têm responsabilidades e riscos, recente queda de viaduto em Belo Horizonte, durante a Copa do Mundo, em 2014 e de ciclovia no Rio de Janeiro, em 2016, mostra a dificuldade de contestar esse argumento.
} 
justificado o surgimento do projeto $A H E L O$, que - se for implementado - avaliaria o desempenho dos estudantes e, especialmente, da educação superior em escala global.

Algumas das atividades de transnacionalização da educação superior, como as filiais internacionais de universidades, a educação à distância, os estudantes internacionais e a imigração qualificada beneficiam-se de mecanismos de aferição de qualidade como rankings e provas. Os rankings informam sobre a qualidade da pesquisa das instituições e o AHELO o faria sobre a qualidade de cursos e instituições, com dados sobre desempenho dos alunos. Ambos forneceriam informações instantâneas sobre a qualidade da graduação dos sujeitos na cada vez mais globalizada sociedade do conhecimento, onde a corrida pelos cérebros já se iniciou. Caso se concretize o projeto $A H E L O$, os Estados nacionais não apenas poderiam perder influência (AFONSO, 2013) sobre o perfil dos seus cursos, processo iniciado com o Projeto Tuning, como também no caso de os países periféricos, poderia ampliar-se ainda mais o seu papel de provedores de cérebros para a sociedade global, em que se apresentam possibilidades de maiores fundos para pesquisa e melhores condições de trabalho e de vida.

As três tendências apresentadas mostram o desenvolvimento da agenda da avaliação da educação superior nas diversas escalas global, regional e nacional e a cada vez maior influência de diversas instituições internacionais (OECD, União Europeia, Mercosul, The Times Higher Education e outras) na geração de políticas de avaliação, em que os Estados Nacionais continuam cumprindo importante papel (DALE, 2010), mas cada vez menos como Estado Avaliador conforme prefigurava Afonso (2013). Com efeito, tanto os rankings quanto o projeto AHELO podem ser consideradas dentro dessa nova fase pós-Estado Avaliador, pela sua gênese via empresas e via OECD.

Ainda, custa imaginar tal grau de futura convergência na educação superior, que poderia comprometer a tão prezada inovação de que a própria sociedade do conhecimento precisa para sua sustentação e reprodução. Onde irá surgir essa inovação na educação superior mundial tão homogênea e padronizada? 


\section{Referências}

AFONSO, Almerindo J. Mudanças no Estado-avaliador: comparativismo internacional e teoria da modernização revisitada. Revista Brasileira de Educação, Rio de Janeiro, v. 18, n. 53, p. 267-284, jun. 2013.

ALTBACH, Philip. The globalization of college and university rankings. Change: The magazine of higher learning, Taylor \& Francis, p. 26-31, jan./fev. 2012. Disponível em: $<$ http://www.tandfonline.com/doi/full/10.1080/00091383.2012.636001?scroll=top\&needAcce ss=true $>$. Acesso em: 15 set. 2014.

ALTBACH, Philip. The past, present, and future of the research university. In:

ALTBACH, Philip; SALMI, Jamil (Orgs.). The road to academic excellence: the making of world-class research universities. Washington: The World Bank, 2011.

ALTBACH, Philip; SALMI, Jamil. Introdução. In: ALTBACH, Philip; SALMI, Jamil (Orgs.).The road to academic excellence: the making of world-class research universities. Washington: The World Bank, 2011.

BARREYRO, Gladys Beatriz; LAGORIA, Silvana Lorena; HIZUME, Gabriella de Camargo. As agências nacionais de acreditação no sistema ARCU-SUL: primeiras considerações. Avaliação, Campinas; Sorocaba, v. 20, n. 1, p. 49-72, mar. 2015.

BATISTA, Juliana Peixoto. El impacto de las negociaciones comerciales internacionales sobre la educación superior: los casos de Argentina y Brasil. Buenos Aires: Eudeba, 2012. BRASIL. Projeto de Lei 4372/2012. 2012. Cria o Instituto Nacional de Supervisão e Avaliação da Educação Superior - INSAES, e dá outras providências. Disponível em: <www.camara.gov.br/sileg/integras/1022352.pdf>. Acesso em: 4 mar. 2015.

COMISSÃO DE APERFEIÇOAMENTO DE PESSOAL SUPERIOR (CAPES). Capes e USP assinam acordo para vinda de docentes do exterior. 2015. Disponível em: $<$ http://www.capes.gov.br/sala-de-imprensa/noticias/7377-capes-e-usp-assinam-acordo-paravinda-de-docentes-do-exterior $>$. Acesso em: 12 mar. 2015.

CARVALHO, Luís Miguel. Governando a educação pelo espelho do perito: uma análise do Pisa como instrumento de regulação. Educação \& Sociedade, Campinas, v. 30, n. 109, p. 1009-1036, set./dez. 2009.

CHOUDANA, Rahul; WIT, Hans de. Challenges and opportunities for global student mobility in the future: a comparative and critical analysis. In: STREITWIESER, Bernhard (Org.). Internationalisation of higher education and global mobility. Oxford: Symposium, 2014. p. 19-33. 
CRUZ, Hélio Nogueira. Parecer da Comissão Gestora do Prêmio Excelência Acadêmica Institucional USP. Blog da USP, 9 dez. 2010. Disponível em:

<http://www.usp.br/imprensa/?p=5990>. Acesso em: 26 nov. 2014.

DALE, Roger. A sociologia da educação e o Estado após a globalização. Educação \& Sociedade, Campinas, v. 31, n. 113, p. 1099-1120, out./dez. 2010.

DALE, Roger. Os diferentes papéis, propósitos e resultados dos modelos nacionais e regionais de educação. Educação \& Sociedade, Campinas, v. 30, n. 108, p. 867-890, out. 2009.

DIAS, Marco Antonio Rodrigues. Comercialização no ensino superior: é possível manter a idéia de bem público? Educação \& Sociedade, Campinas, v. 24, n. 84, p.817-838, set. 2003.

EUROPEAN REGISTER FOR QUALITY ASSURANCE AGENCIES (EQAR). Disponível em: <www.eqar.org>. Acesso em: 15 jan. 2015.

GINKEN, Hans; DIAS, Marco Antônio. Retos institucionales y políticos de la acreditación en el ámbito internacional. In: GLOBAL UNIVERSITY NETWORK FOR INOVATION (GUNI). La educación superior en el mundo 2007. Acreditación para la garantía de la calidad: Qué está en juego? Madri: Mundi Prensa, 2006. p. 37-57.

HARVEY, Lee. Editorial. Rankings of higher education institutions: a critical review. Quality in Higher Education, Abingdon, v. 14, n. 3, p.187-207, nov. 2008.

HERMO, Javier Pablo. La Acreditación Regional de Carreras en el MERCOSUR: presente y futuro. Un estudio de caso sobre la nueva relación entre la globalización y los procesos de convergencia de la educación superior. Berlim: Ed. Académica Española, 2011.

LALANCETTE, Diane. The OECD initiative for an assessment of higher education learning outcomes. Intellectual economics, Vilna, v. 2, n. 8, p. 39-46, 2010.

MORGAN, John. OECD's Ahelo will fail to launch, says education director. The Times Higher education. Londres, 21 set. 2015. Disponível em: <

https://www.timeshighereducation.com/news/oecds-ahelo-will-fail-launch-says-educationdirector>. Acesso em: 15 abr. 2016.

NEAVE, Guy. The Evaluative State, Institutional Autonomy and Re-engineering Higher Education in Western Europe: The Prince and His Pleasure. (Issues in higher education). Basingstoke: Palgrave Mac Millan, 2012.

NUSCHE, Deborah. Assessment of Learning Outcomes in Higher Education: a comparative review of selected practices. OECD Education Working Papers. OECD, 2008. n. 15. Disponível em: <http://dx.doi.org/10.1787/244257272573>. Acesso em: 2 out. 2014. 
ORGANISATION FOR ECONOMIC CO-OPERATION AND DEVELOPMENT - OECD. AHELO. 2012. Disponível em: <http://www.oecd.org/edu/skills-beyondschool/AHELO\%20Brochure.pdf>. Acesso em: 6 jan. 2015.

ORGANISATION FOR ECONOMIC CO-OPERATION AND DEVELOPMENT - OECD. About PISA. Disponível em: <http://www.oecd.org/pisa/aboutpisa/>. Acesso em: 25 fev. 2015.

ORGANISATION FOR ECONOMIC CO-OPERATION AND DEVELOPMENT - OECD. Assessment of Higher Education Learning Outcomes Feasibility Study Report. v. 1 Design and implementation Executive Summary. OECD, 2013. Disponível em: $<$ http://www.oecd.org/edu/skills-beyondschool/AHELO\%20FS\%20Report\%20Volume\%201\%20Executive\%20Summary.pdf>. Acesso em: 15 abr. 2016.

PORTAL MEC. Acreditação de cursos no sistema ARCU-SUL. Disponível em: $<$ http://portal mec.gov.br/index. .php?option=com_content\&view=article\&id=13454:acr $>$. Acesso em: 5 mar. 2015.

RAMA, Claudio. La tercera reforma de la educación superior en América Latina. Buenos Aires: FCE, 2006.

REISBERG, Liz. Onde se encontra a discussão sobre qualidade: Estratégias e ambigüidades, 2011. (mimeogr).

ROBERTSON S.; OLDS, K. World University Rankings: on the new arts of governing (quality). Centre for Globalisation, Education and Societies, University of Bristol, UK, 2012. Disponível em: <http://susanleerobertson.com/publications/>. Acesso em: 20 nov. 2015.

ROBERTSON Susan; DALE, Roger. The social justice implications of privatisation in education governance frameworks: a relational account. Special Issue-Education, Privatisation and social justice. Oxford Review of Education, Oxford, v. 39, n. 4, p. 426445, 2013.

SGUISSARDI, Valdemar. Regulação estatal e desafios da expansão mercantil da educação superior. Educação \& Sociedade, Campinas, v. 34, n. 124, p. 943-960, set./dez. 2013.

TUNING AMÉRICA LATINA. Disponível em:

$<$ http://tuning.unideusto.org/tuningal/index.php>. Acesso em: 12 jan. 2015.

UNIVERSIDADE DE SÃO PAULO - USP. Resolução n 5483 de 6 de nov. de 2008. Diário Oficial da União, 8 nov. 2008. Disponível em:

$<$ http://www.leginf.usp.br/?resolucao=consolidada-resolucao-no-5483-de-6-de-novembro-de2008>. Acesso em: 6 nov. 2014. 
UNIVERSIDADE DE SÃO PAULO - USP. Resultado da busca por ranking. Disponível em: <http://www.usp.br/imprensa/?tag=ranking> Acesso em: 3 dec. 2014.

Gladys Beatriz Barreyro Universidade de São Paulo | Escola de Artes, Ciências e Humanidades | Programa de Pós-Graduação em Educação São Paulo | SP | Brasil | Contato: gladysb@usp.br ORCID (iD http://orcid.org/0000-0002-2714-5811

Artigo recebido em 30 de abril de 2016 e aprovado em 14 de julho de 2016. 